\title{
Correction to: Inventory and Quantitative Valuation of Geological and Geomorphological Sites from Gilgit-Baltistan, Northern Pakistan
}

\author{
Javed Akhter Qureshi ${ }^{1} \cdot$ Muzammil Khan ${ }^{1} \cdot$ Shehzad Sikandar $^{1} \cdot$ Garee Khan $^{1} \cdot$ Naeem Abbas ${ }^{2} \cdot$ Asghar Khan $^{1}$. \\ Muhammad Alam $^{1} \cdot$ Rehmat Karim $^{3} \cdot$ Sarah J. Halvorson ${ }^{4}$
}

Published online: 2 December 2021

(c) The Author(s), under exclusive licence to The European Association for Conservation of the Geological Heritage 2021

\section{Correction to: Geoheritage (2021) 13:94}

$$
\text { https://doi.org/10.1007/s12371-021-00617-0 }
$$

The section comprising "GB Landscapes and Geosite Selection" in this article must be deleted as it is an editorial comment that was not removed at the completion stage.

The original article has been corrected.

The original article can be found online at https://doi.org/10.1007/ s12371-021-00617-0

Javed Akhter Qureshi

javed.akhter@kiu.edu.pk

1 Department of Earth Science, Karakoram International University, Gilgit 15100, Pakistan

2 Department of Mining Engineering, Karakoram International University, Gilgit 15100, Pakistan

3 Department of Tourism and Hospitality Management, Karakoram International University, Gilgit 15100, Pakistan

4 Department of Geography, W.A. Franke College of Forestry and Conservation, University of Montana, Missoula, MT, USA 